\title{
Medical Image of the Month: Severe Left Ventricular Hypertrophy
}

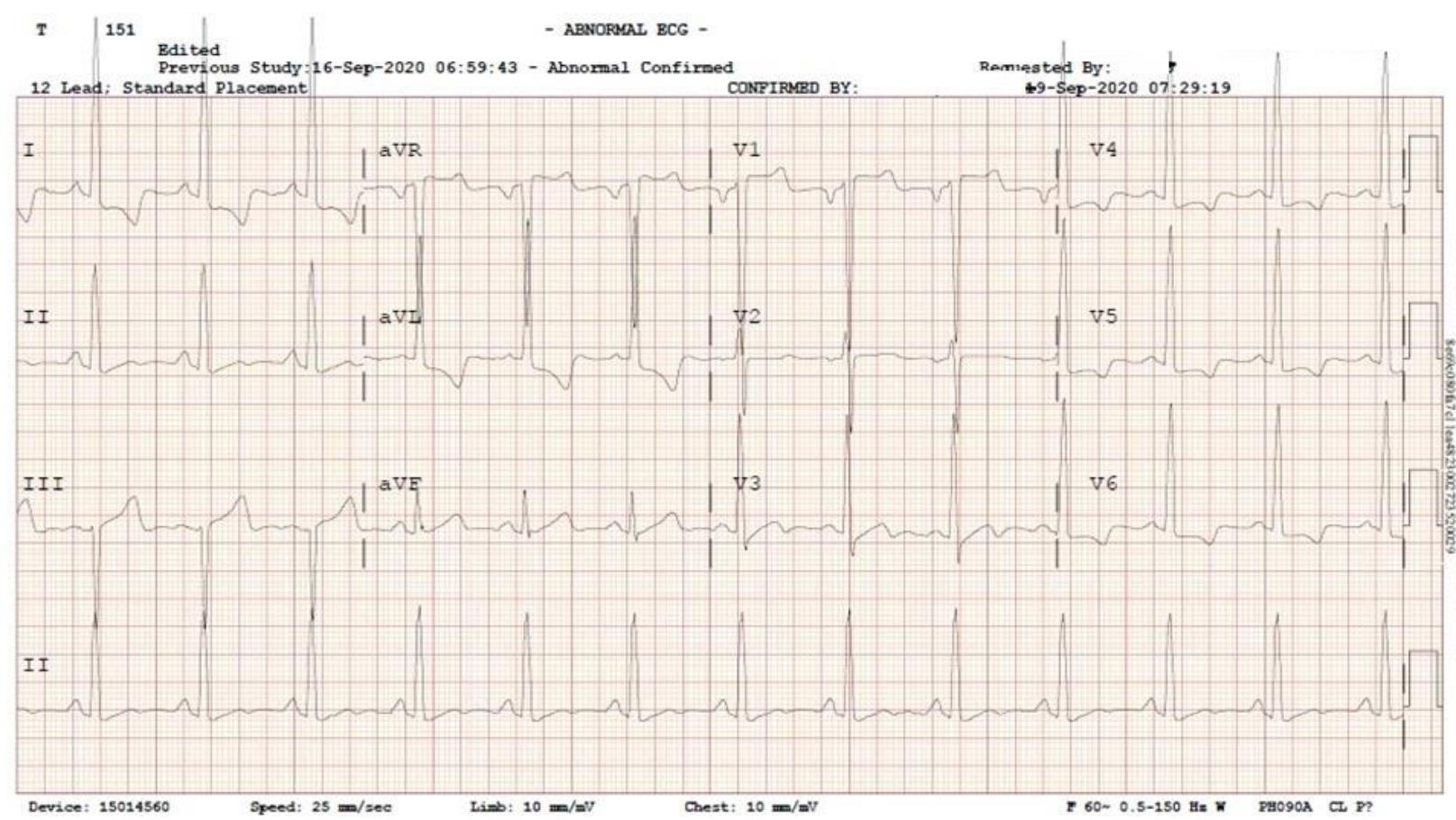

Figure 1. An electrocardiogram demonstrates left ventricular hypertrophy by voltage and non-voltage criteria.

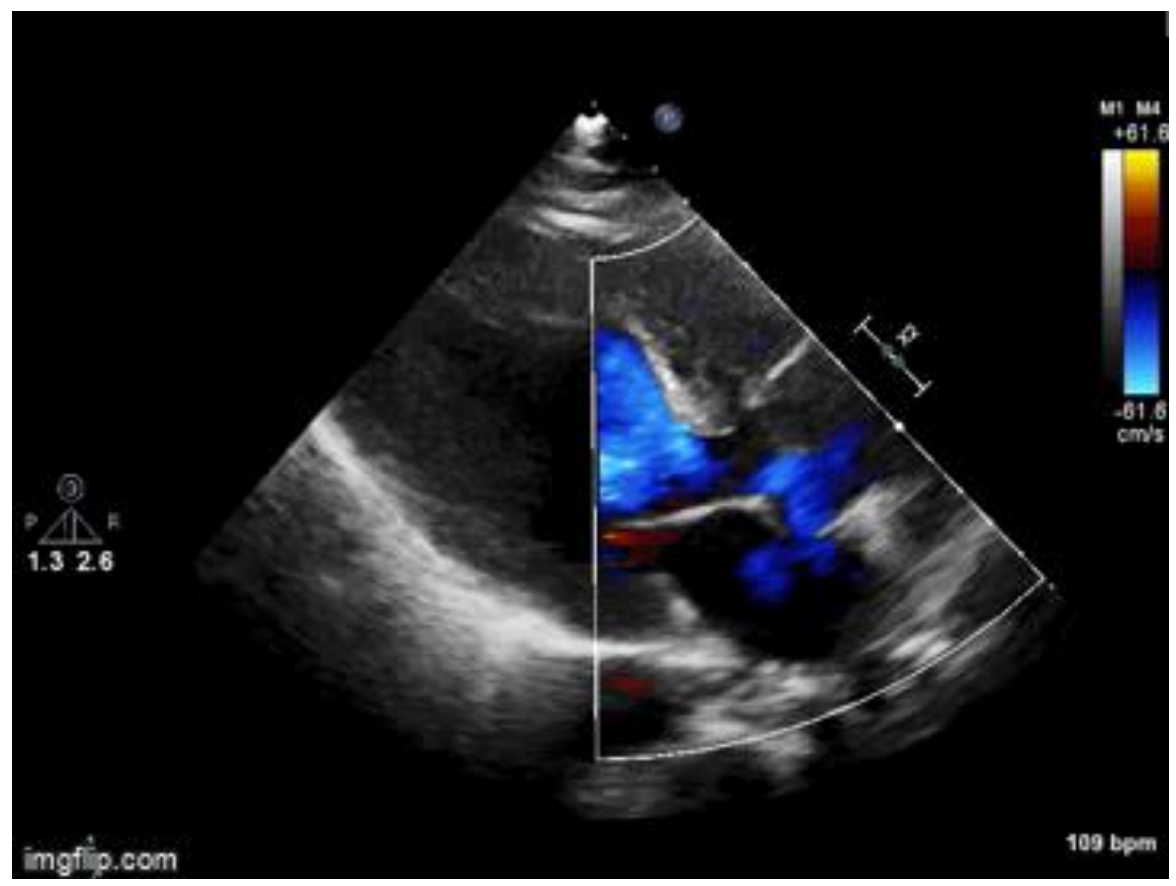

Figure 2. Parasternal long view of the heart demonstrates marked left ventricular hypertrophy with partial obstruction of the left ventricular outflow tract. 
The patient is a 56-year-old man with a history of hypertension who was admitted to ICU after the administration of nitroglycerin for chest pain in the setting of hypertensive emergency resulted in a sudden drop in systolic BP drop from 220 to 106. The above images depict LVH on EKG (Figure 1) along with severe concentric LVH (End-diastolicwall-thickness $=22 \mathrm{~mm}$ ) with significant apical and septal thickening resulting in partial obstruction of the left ventricle outflow tract concerning for HCM vs HHD (Figure 2).

Significant morphological overlap between HCM and HHD makes establishing a diagnosis difficult and often requires more advanced tissue characterization in the form of cardiac MR. In a patient with severe LVH, a diagnosis of HCM should be considered if $\geq 1$ myocardial segment has a LV end-diastolic wall thickness (EDWT) $\geq 15 \mathrm{~mm}$ on transthoracic echo ${ }^{1}$. Additional features such as systolic anterior motion of the mitral valve (SAM) are also useful in establishing a diagnosis of HCM, especially in those with concomitant hypertension. A large majority of patients with HCM have elongated mitral valve leaflets which can protrude into the LV cavity. During systole, the mitral valve leaflet moves towards the interventricular septum which is thickened in patients with $\mathrm{LVH}$. This creates a left ventricular outflow obstruction (LVOTO) that causes shortness of breath, chest pain, and syncope. This ultimately increases the risk of arrhythmias and sudden cardiac death.

Treatment of LVOT obstruction is indicated in all symptomatic patients. First line medical management functions to increase preload with negatively inotropic medications such as beta-blockers, disopyramide and verapamil. In patients who are persistently symptomatic despite optimal medical therapy, septal reduction therapy via alcohol septal ablation (ASA) or septal myomectomy (SM) are standard of care ${ }^{2}$. Longterm data suggests there is no difference in cardiovascular mortality when comparing ASA and SM. However, those receiving ASA have lower periprocedural complications but more often require implantation of pacemakers or reintervention in the future.

April L. Olson MD MPH, Nicholas G. Blackstone MD, Benjamin J. Jarrett MD, and Janet M. Campion MD MPH University of Arizona College of Medicine at South Campus Tucson, AZ USA

\section{References}

1. Rodrigues JC, Rohan S, Ghosh Dastidar A, Harries I, Lawton CB, Ratcliffe LE, Burchell AE, Hart EC, Hamilton MC, Paton JF, Nightingale AK, Manghat NE. Hypertensive heart disease versus hypertrophic cardiomyopathy: multi-parametric cardiovascular magnetic resonance discriminators when end-diastolic wall thickness $\geq 15 \mathrm{~mm}$. Eur Radiol. 2017 Mar;27(3):1125-1135. [CrossRef] [PubMed]

2. Osman M, Kheiri B, Osman K, Barbarawi M, Alhamoud H, Alqahtani F, Alkhouli M. Alcohol septal ablation vs myectomy for symptomatic hypertrophic obstructive cardiomyopathy: Systematic review and meta-analysis. Clin Cardiol. 2019 Jan;42(1):190-197. [CrossRef] [PubMed] 